
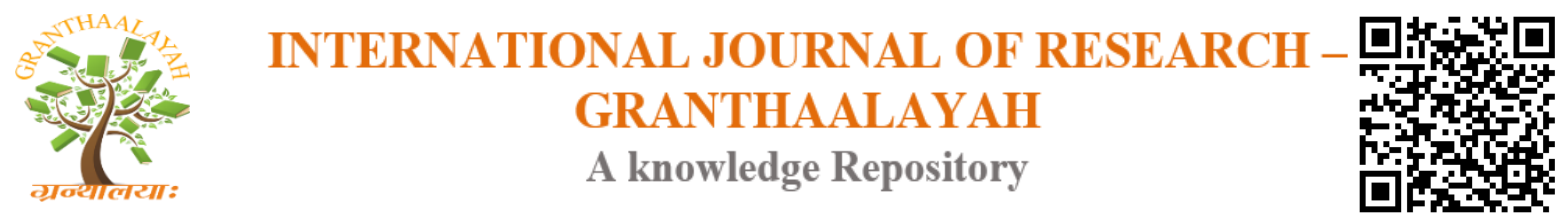

Social

\title{
THE STANDARDS FOR ENSURING THE QUALITY OF EDUCATION IN KOSOVO ACCORDING TO EUROPEAN STANDARDS OF THE HIGH EDUCATION
}

\author{
Dr. Sc. Safet Krasniqi *1 \\ ${ }^{* 1}$ University of Prizren “Ukshin Hoti” University College "FAMA”, Republic of Kosova
}

\begin{abstract}
Ensuring the existing capacities as a basic condition for a quality education, in education is connected in the beginning with a level of consciousness that captures in itself the need of educational planning building. These mechanisms despite that they are legal it has also to do with building up the capacities through twinning projects, funded by EU. The planning process has started by the SWOT program. The analyses showed weak points for ensuring the quality in education and they are separation of responsibilities between institutions. What is indispensable in Kosovo, it is building mechanisms to ensure quality assessment. The methods used in this paper are more research of materials and less comparative as far as the course and previous actions in Kosovo education. It is approved and entered into effect the law for education and capacity enhancement in Kosovo that aims supplying the people of all ages with professional knowledge. During the theses paper we are going to elaborate wider many theoretical and practical issues which deal with intentions, strategies and European standards which coordinate possibilities of accomplishment of objectives and ranking Kosovo education within education of European countries.
\end{abstract}

Keywords: Standard; SSWOT; EU; Standards.

Cite This Article: Dr. Sc. Safet Krasniqi. (2018). "THE STANDARDS FOR ENSURING THE QUALITY OF EDUCATION IN KOSOVO ACCORDING TO EUROPEAN STANDARDS OF THE HIGH EDUCATION." International Journal of Research - Granthaalayah, 6(5), 59-64. https://doi.org/10.29121/granthaalayah.v6.i5.2018.1426.

\section{Introduction}

The purpose of this paper is the minimal clarification of the education state in Kosovo, the circumstances presented after 1999 and especially with the harmonization with EU legislation, towards the creation of new experiences in education, these experiences are part of adaptation of theoretical education to the practical one, professional training and achieving suitable quality in relation with labor market. Currently theoretical teaching is increasingly dominating in our education. This is evidenced by the International Monitoring Organizations in Kosovo. In their annual reports they have evidenced the educational institutions that are responsible for raising the 
level of education through a teaching and the continuous individual and group education. The other case is the curriculum education design, that means the students should be active in the creation of teaching process, diversity of students, the appreciation and adaption of pedagogical method, the promotion of common respect in teaching, student-teaching, appreciate procedures for handling student complains etc.

Kosovo Education Institutions, after 2010, adjusting to the new situations, function according to several new concepts, adequate with the education system in Europe. In Kosovo it is held a theoretical study in the schools, practical study in the cabinets, schools, companies and laboratories. Theoretical study currently is not sufficient, because it has to be adjusted with the practical study in order to achieve learning the occupation. According to a survey, representation of vocational schools in percentage varies from $0.5 \%$ in the trade and to $13.3 \%$ in the mixed directions. The representation of vocational schools according to the percentage continues in the medicine $13,6 \%$, economy $23.9 \%$, music $0.9 \%$, trade $0.5 \%$ and in art $1.1 \%$.

There's enough endeavors finding ways to increase the efficiency in addressing the economical request in the job market. High Professional Education Institutions (IAP) in Kosovo are in the stage of orientation for the job market and there's an endeavor for having a vision for the national system of IAP, which is connected by the efficiency and efficacy in addressing of economical requests those demographic, social etc. Upon these basis was drafted, approval of the Law upon capacity enhancement and professional education. This is connected by general principles defined with general norms and special ones, which determine the notion of professional education, Institutions of professional education, theoretical and practical studies etc. What is more important according to this law are intentions that wants to achieve this law and the beneficiaries by this law. Upon this aspect the development of competences and employment of individuals in accordance with their future professions, general culture that is gained etc. and particularly beneficiaries are Companies and economy generally.

Along this law, the Kosovo Assembly approved another law that deals with education and capacity enhancement of adults by the number 02/L-24. This law determines the manner and adjustment of education system for adults within the field of activity of this law, which deals with education and capacity enhancement for adults in accordance with new standards, this form of capacity enhancement is organized in the accredited Institutions and licensed by MEST, in this aspect MEST has the competence of supervision and application of this law by licensed entities and accredited by International Organizations, which are present in Kosovo, whether in the capacity of monitoring and in the capacity of direct supporters. They drafted short term reports and various strategies about strategies for cooperation and development of the country, in this context and the growth of education in Kosovo.

It is worth to mention the strategy for cooperation and growth of the country for the period 20142108 drafted by USAID. After a successful addressing of challenges in the primary level from the classes 1-9, USAID will request the possibility to register and analyze shortages in high schools, classes 10-12. This will enable students to progress in the education system. Having the opportunity for high education, those students will gain advanced knowledge for the whole life. Now the high school in Kosovo doesn't provide knowledge and practical capacity enhancement and doesn't produce graduated students who are capable for employment. However, the 
abovementioned evaluation HICD identifies priority fields for reforms, e.g. within public administration, IT, Agriculture and thus it affords to USAID the possibility to assist, improve professionalism and pedagogies in the selected Faculties, as long as assures fulfillment by other program elements. Each support for the selected Faculties will be combined with the chosen possibilities by the attention for short-term and long-term trainings in the International level (basically in USA). Additional support for Prishtina University, as a concrete example beyond technical assistance that is part of partnership with American schools, by the education possibility abroad, will depend by achieving certain intentions. Currently, an action plan is being drafted in the process of participation by inclusion of MEST Officials, and University Deans, donors and members of the development community. -The plan has accepted attention and considerable support and exists every indication for achievement of expected progress. The progress in this action plan will create the base for preliminary conditions for additional support. Knowing the top level of contributions by the Government of Kosovo about the USAID education programs in Kosovo, approximately $50 \%$ in the Primary and High education, exists a powerful partnership as well as the support for the additional job in both intermediate results during coming years.

Within drafting and setting the framework for ensuring the quality in High education, it is worth to mention drafted standards and approval by the Following Group of Bologna, September 2014, which is sent for approval in the Ministerial Conference of 2015 This strategy is sent for approval by the relevant and competent institutions of education such as: European Association for Security of Quality in High Education, European Union of Students, Association of European Universities etc.. A key goal of standards and Guidelines for ensuring the quality in the European Space of High Education (ESG) is a contribution for the common good understanding to ensure the quality for learning and teaching beyond borders and among all actors. Teaching and active learning and other education sources are basic extended criteria determined by the relevant education Institutions of European Union.

The ESG purpose deals with teaching and learning in high education calculating also the environment of education and opportunities of scientific researches. They are more important for securing the quality in high education such as responsibility and improvement. Institutions should have policies for ensuring the quality that become public and consist part of strategies of management as per ensuring the policy of quality, drafting and approving programs that should include students, benefits by exchanging experiences of various countries in education, accomplishment of intentions and concepts of the European Council, realization of the constant progress to advance knowledge, the burden of the work for the students as per ECTS etc and opportunity of good structured employment.

Within ensuring standards are also learning and teaching which i.e. that students have an active role to create an education process, diversity of students, assessment and adjustment of pedagogical methods, promotion of the common respect in teaching, student-teacher, adaptable procedures to treat complaints of students etc. beginning from principles determined by International Organizations, which deal with education in general and high education in particular. R. of Kosovo drafted a strategy with the purpose of implementation of Regulations and procedures as per the quality of high education. This is seen also in the legal framework drafted by MEST taking into account the responsibility that has for planning education development. Kosovo Accredited Agency is a key institution for external evaluation of quality, strategic development 
and NQF maintenance (National qualification Framework) that deals with all types of qualifications. MEST through National Center for Acknowledgement and Academic Information (NARIC) is responsible for drafting policies and practices for acknowledgment of qualifications achieved abroad.

Decisions for acknowledgement of qualifications gained abroad are done by the National Acknowledgement Council. According to the law for High Education, responsibilities of KAA include, Councils with the Minister, from time to time inspections, inspections of bidders of high education, periodical assessments, counseling of the Ministry regarding the results of assessment of quality etc. National Qualification Framework is established for a several period of time. Its establishment preceded consultations, seminars and International Conferences, which are organized in Prishtina. In 2004 the first Seminary was held in Kosovo, where the participants were from West Balkans countries. The seminary was conducted and endorsed by the European Training Foundation and the participants were informed that the European Commission is a process of development of the European Qualification Framework.

In 2005 a working group from Kosovo paid a studying visit in Ireland. This place was selected taking into account the fact that has a very developed KKK. The working group called the Dublin Group, that paid this visit consisted by the MEST representatives, OEK; Kosovo Independent Trade Union, two members of the Education Commission and a representative by the Civil Society. Also in 2006 during a 5 day Workshop, a large group began drafting the law for KKK. In 2007 was held a Workshop to review the proposals, and they agreed that exists the need to create a Task Force in AKK, which can act as an AKK in the shade and a Working Group for KKK which can project KKK.

In 2014, the European Training Foundation (FET) undertook the third round of the Torino Process, where Kosovo participated. The Torino Process is a participation review of progress in education policies and professional capacity enhancement (APP) which is conducted every second year from all partner countries of FET, by the support e FET. This report mentions in details organs and Institutions that deal with building up education in all levels. It also shows the level of economical progress of Kosovo, age of population, labor market and the opportunity of adaptation of requests and completion of the school.

A concrete example is also the strategy of enlargement and ensuring the quality in the University "Ukshin Hoti" in Prizren. This project is financed by the support of European Commission. This strategy envisages the possibility of building up the education capacities of the University, based on the management role, academic staff and administrative one. Guaranteeing the transparence, freedom of studies and artistic research, respecting of study inclusion and better manner of strengthening.

Compliance and comparison of studying programs with standards and European guidelines by external accreditation of Institutions and programs, UPz will achieve compliance by the requests of European High Education. This process will enlarge the opportunity for the graduates in order to continue their studies in various regional Universities, European and worldwide. In March 2012, Management of the University in Prizren has established the Office of Ensuring the Quality by the duty of relieving of implementation of principles registered above. In the national and European 
level, the Prizren University is engaged to use as guideline documents within the Field of European High Education as well as those of Republic of Kosovo, which implies the Bologna Declaration, Standards and Guidelines of Ensuring the Quality in the Field of European High Education, European Association for Ensuring the Quality of High Education, Lisbon Convention, Kosovo Education Law for High Education and Guidelines of Kosovo Accreditation Agency

\section{Motivation:}

Practical teaching, teaching and the active role of students is still a problem. The problem lies in providing learning environment that enables qualitative improvement in education. The adaption of new standards of vocational education consist by a special challenge. Ensuring transparency freedom of study and scientific research through curriculum compiled according to International Standards is a process that canot be accomplished for a short time but it will be a long process that takes time, readiness and creative will.

\section{The Essential if this Work is}

Is Kosovo ready to face new challenges in vocational education? I believe that the Ministry of Education of Kosovo, is trying through seminars, international conferences and legislative frames to increase the quality of vocational education with EU standards and the finding a way to increase efficiency in a addressing labor market demands. Efforts depend on the degree of cooperation and cooperation with International Organizations dealing with education issues.

\section{Method}

During the design of this work, often are used comparative methods and analytically. Has been excluded historical method because of the situations that has passed education in Kosovo for many decades.

\section{Results}

The problem solving that education has in Kosovo today, especially the need for adaption of theoretical education with practical education. Professional schools are necessity for practical evidence of internal and external market needs EU, quality assurance standards including the Recommendation of the committee of Ministers of the Europe Council has evidenced the need for adaptation of the Law on Education, International cooperation and organizing trainings for establishment of academic staff with a purpose for adaptation of new methods of education.

\section{Conclusion}

General streams in the world, certainly have a special impact in Kosovo. Especially in the education process, that is the subject of this topic. This deals more with enhancement and advancing the quality in education, generally targeting harmonization our legislation and establishing a practice, which is compatible with European education in general.

Actually, the endeavors of Kosovo Institutions are not sufficient as per the application of this legislation in practice taking into account the scale of education enhancement, consequences from 
the past and above all, shortage and creation of a vision for the future of Kosovo education in general. Objectively, MEST should have this as objectives;

- Periodical inspection of education institutions not only legal side but also practical application of law and other judiciary acts,

- Management inspection of public and private education as per engagement of academic staff, influence that has frequent change of the staff;

- Looking the scale of application of contract of employment and monthly payment period for the academic staff and private institutions and

- Establishment of Institutions for scientific researches of high education, especially in the private sector.

\section{References}

[1] AAP in Kosovo in the period 2010-2015, Prishtinë, 2010

[2] Law for Education and Kosovo Professional capacity enhancement, article 1

[3] Law for Education and capacity enhancement for adults No.02/L-24, article 4, 5, 6, 7 and 8

[4] USAID, Strategy for cooperation and development of the country Kosovo, 2014-2018, page. 12

[5] Standards and Guidelines for Ensuring the Quality in the European Space of High Education (SUE), September, 2014

[6] http://ec.europa.eu/education/neës/doc/openingcom_en.pdf

[7] Recommendation Rec. (2007)6 by the Commission of Ministers of European Council upon public responsibility for high education and research

[8] Standards and Guidelines for Ensuring the Quality in the European Space of High Education (SUG) approved by the Forwarding Bologna Group, September, 2014, pg. 14-15

[9] Torino process, 2014, European Training Foundation, 2015, Reproduction is authorized provided the source is acknowledged

[10] Strategy of enlargement and Ensuring the Quality of for the University "Ukshin Hoti" in Prizren, 213, pg. $9-10$

\footnotetext{
*Corresponding author.

E-mail address: safet.krasniqi@ uni-prizren.com
} 